Article

\title{
Azadirachtin Attenuates Lipopolysaccharide-Induced ROS Production, DNA Damage, and Apoptosis by Regulating JNK/Akt and AMPK/mTOR-Dependent Pathways in Rin-5F Pancreatic Beta Cells
}

\author{
Annie John (i) and Haider Raza * \\ Department of Biochemistry and Molecular Biology, College of Medicine and Health Sciences, \\ United Arab Emirates University, Al Ain P.O. Box 17666, United Arab Emirates; anniej@uaeu.ac.ae \\ * Correspondence: h.raza@uaeu.ac.ae; Tel.: +971-3-7137506
}

check for

updates

Citation: John, A.; Raza, H.

Azadirachtin Attenuates

Lipopolysaccharide-Induced ROS

Production, DNA Damage, and

Apoptosis by Regulating JNK/Akt

and AMPK/mTOR-Dependent

Pathways in Rin-5F Pancreatic Beta

Cells. Biomedicines 2021, 9, 1943.

https://doi.org/10.3390/

biomedicines 9121943

Academic Editor: Satoshi Wada

Received: 16 November 2021

Accepted: 16 December 2021

Published: 18 December 2021

Publisher's Note: MDPI stays neutral with regard to jurisdictional claims in published maps and institutional affiliations.

Copyright: (c) 2021 by the authors. Licensee MDPI, Basel, Switzerland. This article is an open access article distributed under the terms and conditions of the Creative Commons Attribution (CC BY) license (https:// creativecommons.org/licenses/by/ $4.0 /)$

\begin{abstract}
Pancreatic inflammation and the resulting cellular responses have been implicated in pancreatitis, diabetes, and pancreatic cancer. Inflammatory responses due to the bacterial endotoxin, lipopolysaccharide (LPS), have been demonstrated to alter cellular metabolism, autophagy, apoptosis, and cell proliferation in different cell populations, and hence increases the risks for organ toxicity including cancer. The exact molecular mechanism is however not clear. In the present study, we investigated the role and mechanism of an antioxidant, azadirachtin (AZD), a limonoid extracted from the neem tree (Azadirachta indica), against LPS-induced oxidative stress in the pancreatic $\beta$-cell line, Rin-5F. We demonstrated that cells treated with LPS $(1 \mu \mathrm{g} / \mathrm{mL}$ for $24 \mathrm{~h})$ showed increased reactive oxygen species (ROS) production, DNA damage, cell cycle arrest, and apoptosis. Our results also showed that LPS induced alterations in the AMP-activated protein kinase (AMPK)/mammalian target of rapamycin (mTOR) pathways, suppressing autophagy and augmenting apoptosis. Treatment with Azadirachtin ( $25 \mu \mathrm{M}$ for $24 \mathrm{~h}$ ), on the other hand, rendered some degree of protection to the pancreatic cells from apoptosis by inducing the autophagy signals required for cell survival. These results may have significance in elucidating the mechanisms of pancreatic $\beta$-cell survival and death by balancing the molecular communication between autophagy and apoptosis under inflammatory and pathological conditions.
\end{abstract}

Keywords: pancreatic cells; LPS; azadirachtin; ROS; apoptosis; autophagy

\section{Introduction}

Lipopolysaccharide (LPS), a bacterial endotoxin, induces septic shock, which may result in multiple organ dysfunction. The release of inflammatory mediators, such as tumor necrosis factor (TNF- $\alpha$ ) and interleukins are considered to be the main triggers inducing cellular response and organ dysfunction [1]. These pro-inflammatory mediators are also responsible for initiating the cascade of secondary factors and signaling of autophagy, apoptosis, or cellular proliferation [2-6]. Homeostasis of pro-inflammatory and anti-inflammatory responses have also been implicated in a number of diseases $[7,8]$. Inflammatory stress promotes oxidative stress and vice versa. A high-fat diet can cause alterations in gut microbiota and induce up to three-fold lipopolysaccharide production, contributing to increased oxidative and ER stress, glucotoxicity, and lipotoxicity-associated complications, resulting in decreased pancreatic functions and triggering type 2 diabetes (T2D) development [9-11]. LPS-induced pancreatitis and $\beta$-cell mass destruction have been reported to be due to increased reactive nitrogen species and inflammatory signaling [12-14].

Using both in vivo animal models for type1 and type 2 diabetes [15-19] as well as in vitro models for glucolipotoxicity in different cellular models [20-23], our laboratory has demonstrated the significance of inflammation, oxidative stress, redox homeostasis, 
mitochondrial dysfunction, and reprogramming of energy metabolism in diabetes. The aim of the present study was to identify protective mechanisms of a potent anti-inflammatory compound, isolated from neem, on LPS-induced inflammation in a cell culture system using the insulin-secreting pancreatic beta cell, Rin-5F.

Azadirachtin (AZD), a phytochemical limonoid extracted from neem (Azadirachta indica) leaves and fruit, with known anti-inflammatory properties, has been reported to be beneficial in a number of inflammatory and oxidative stress-related abnormalities for more than 2000 years. In many degenerative disorders including diabetes, and various types of cancers including pancreatic cancer, the potential of neem plant extract is considered to be due to the abundant presence of the active limonoid, azadirachtin. Azadirachtin and related limonoids have been shown to protect $\beta$-cells from oxidative and inflammatory stressinduced cytotoxicity by manipulating the cell signalling kinases and anti-inflammatory responses [24-28]. The present study focuses on the identification of biochemical markers in Rin-5F cells affected by LPS treatment and the mechanism of protection of cytotoxicity by AZD. We report here that AZD alters $\beta$-cells' responses towards oxidative/inflammatory stress by regulating cellular DNA damage, cell proliferation, and cellular signalling pathways regulating autophagy and apoptosis.

\section{Materials and Methods}

\subsection{Materials}

Azadirachtin (AZD, \# A7430)), LPS (\# L6511), 3-(4,5-dimethylthiazol-2-yl)-2,5diphenyltetrazolium bromide (MTT, \# M2128), propidium iodide (\# P4170), Hoechst 33,342 (\# B2261), and cellular DNA fragmentation ELISA kits (\# 11585045 001) were purchased from Sigma-Aldrich (St Louis, MO, USA). 2,7-Dichlorofluorescein diacetate (DCFDA, \# D399) was purchased from Molecular Probes, Inc. (Eugene, OR, USA). Kits for caspase-3 (\# BF3100) and -8 assays (\# K113-25) were procured from R\&D Systems (Minneapolis, MN, USA). Apoptosis detection kits (\# 556547) for flow cytometry were purchased from BD Pharmingen (BD Biosciences, San Jose, CA, USA). Rin-5F cells (\#CRL-2058) were obtained from the American Type Culture Collection (Manassas, VA, USA). Polyclonal antibodies against cleaved caspase-3 (\# 9661), poly (ADP-ribose) polymerase (PARP, \# 9542)), autophagy-related protein (Atg5, \# 8540)), microtubule-associated light chain 3 (LC3, \# 2775), SQSTM1/p62 (\# 5114), c-Jun N-terminal kinase (SAPK/JNK, \# 9252), phosphorylated c-Jun N-terminal kinase (p-SAPK/JNK, \# 9255), protein kinase B (AKT, \# 4691), phosphorylated protein kinase B (p-AKT, \#4060), AMP-activated protein kinase $\alpha$ (AMPK $\alpha, \# 2532)$, phosphorylated AMP-activated protein kinase $\alpha$ (p-AMPK $\alpha$, \# 2531), mammalian target of rapamycin (mTOR, \# 2972), and phosphorylated mammalian target of rapamycin ( $\mathrm{p}$ mTOR, \# 2971) were purchased from Cell Signaling Technology, Inc. (Danvers, MA, USA). Monoclonal antibodies against heat shock protein (Hsp-70, \#H 5147) were purchased from Sigma-Aldrich (St Louis, MO, USA) while heme oxygenase-1 (HO-1, \#ab 13243) was from Abcam (Cambridge, England, UK) and cyclin B1 (\#sc-7393), p21 (\#sc-6246), and $\beta$-actin (\#sc-47778) from Santa Cruz Biotechnology Inc. (Santa Cruz, CA, USA).

\subsection{Methods}

\subsubsection{Cell Culture and Treatment}

Rin-5F cell line is an insulin-secreting, epithelial pancreatic cell line derived from rat islet beta cells. The cells were cultured in RPMI-1640 GlutaMax medium supplemented with $10 \%$ foetal bovine serum in the presence of $5 \% \mathrm{CO}_{2}-95 \%$ air at $37{ }^{\circ} \mathrm{C}$ as described before $[20,21,29]$. Cells cultured to $80 \%$ confluence were treated with $1 \mu \mathrm{g} / \mathrm{mL}$ of the bacterial endotoxin, LPS for $24 \mathrm{~h}$, based on literature reports and our previous studies [22,30,31]. In some cases, cells were treated with $25 \mu \mathrm{M}$ azadirachtin for $24 \mathrm{~h}$ alone or in combination with LPS. After the desired time of treatment, cells were harvested, washed with PBS ( $\mathrm{pH}$ 7.4), and homogenized and lysed in the appropriate lysis buffers required for the assays as described before $[20,21,29]$. 


\subsubsection{Cell Viability, DNA Damage and Apoptosis Assays}

MTT assay was used to determine the mitochondrial dehydrogenase-based cellular viability. Briefly, cells treated with LPS and/or AZD were assessed for cell viability by the reduction of MTT dye to form insoluble purple formazan crystals, which were dissolved in acidified alcohol and the viable cells quantitated using an ELISA reader (TECAN Infinite M200 PRO, Austria) at $550 \mathrm{~nm}$ as described before [20,21].

DNA damage by apoptosis was assessed using Hoechst 33,342 dye staining of fragmented nuclei. Briefly, cells grown on coverslips were treated with LPS and/or AZD for $24 \mathrm{~h}$ and fixed with $3.7 \%$ formaldehyde. The cells were then stained with Hoechst 33,342 and observed by fluorescence microscopy (Olympus Corporation, Tokyo, Japan). Apoptotic cells showed fragmented nuclei. Oxidative stress-induced DNA damage was also measured after electrophoresis of DNA from LPS and/or AZD-treated cells and staining with ethidium bromide.

Cellular DNA damage was also measured using the cellular DNA fragmentation kit (Sigma-Aldrich, St Louis, MO, USA) as per the vendor's protocol. Briefly, cells were grown to confluency and cell count adjusted to around $2 \times 10^{5}$ cells $/ \mathrm{mL}$ medium and labeled with $5^{\prime}$-bromo- $2^{\prime}$-deoxy-uridine (BrdU, used as a metabolic labeling agent by the nuclear DNA of target cells). After an overnight incubation at $37^{\circ} \mathrm{C}$, cells were centrifuged and resuspended in BrdU-free culture medium. The BrdU-labeled cells $\left(1 \times 10^{5}\right.$ cells $\left./ \mathrm{mL}\right)$ were then treated with LPS and/or AZD for $24 \mathrm{~h}$. After treatment, the cells were lysed to extract the apoptotic DNA fragments from the cytoplasm. The cell extracts were then transferred to 96-well microtiter plates, which were pre-coated with anti-DNA antibody overnight and treated with blocking buffer to block all the non-specific binding sites. The plates with the cell extracts were incubated for $90 \mathrm{~min}$ at room temperature followed by washing the wells. The DNA in the samples were then fixed and denatured and then treated with antiBrdU-peroxidase conjugate solution. After an incubation for $90 \mathrm{~min}$ at room temperature, a substrate was added and incubated in the dark until color development was sufficient, stop solution was added, and measurement was taken at $450 \mathrm{~nm}$ using a plate reader (TECAN Infinite M200 PRO, Austria).

Apoptosis in the LPS and/or AZD-treated cells were measured using a Becton Dickinson FACSCanto II analyser (BD Pharmingen, BD Biosciences, San Jose, CA, USA) as described before [22,31]. Briefly, Rin-5F cells were treated with LPS and/or AZD for $24 \mathrm{~h}$ and re-suspended in binding buffer (10 mM HEPES, pH 7.4, $140 \mathrm{mM} \mathrm{NaCl}, 2.5 \mathrm{mM} \mathrm{CaCl}_{2}$ ) at a concentration of $1 \times 10^{6}$ cells $/ \mathrm{mL}$. A fraction of this cell suspension $\left(1 \times 10^{5}\right.$ cells $)$ was then incubated with FITC-conjugated Annexin V and propidium iodide. After $15 \mathrm{~min}$, binding buffer was added and viable, apoptotic and necrotic cells were measured by flow cytometry.

Caspase- 3 and caspase- 8 activities were measured in the cell lysate using the caspasespecific peptide substrates, Ac-Asp-Glu-Val-Asp (DEVD) and Ac-Ile-Glu-Thr-Asp (IETD) respectively, conjugated to the chromophore, p-nitroanaline. Cleavage of this peptide by the respective caspases releases the chromophore, which is measured colorimetrically at a wavelength of $405 \mathrm{~nm}$ as recommended in the vendor's protocol (R\&D Systems) as described before [20,29].

\subsubsection{Measurement of Intracellular Reactive Oxygen Species (ROS)}

DCFDA, a cell permeable probe, which measures peroxides preferentially was used to measure the intracellular ROS production. LPS and/or AZD-treated cells were incubated with DCFDA and the fluorescence analyzed fluorometrically using the ELISA reader (TECAN Infinite M 200 PRO, Austria), microscopically using the Olympus fluorescent microscope (Olympus Corporation, Tokyo, Japan) and by flow cytometry using the FACSCanto II Flow Cytometer (Beckton Dickinson, San Jose, CA, USA) as described before $[21,32]$. 


\subsubsection{Cell Cycle Analysis by PI Staining}

For cell cycle analysis, Rin- $5 \mathrm{~F}$ cells were fixed with $70 \%$ ethanol, treated with renatured RNaseA and stained with propidium iodide (PI) after treatment with LPS and/or AZD for $24 \mathrm{~h}$ and the different stages of cell cycle analyzed by flow cytometry as described by Piazza et al. [33]. The total DNA content was quantified at an excitation wavelength of $488 \mathrm{~nm}$ and detection wavelength of $620 \mathrm{~nm}$ using the FACSCanto II Flow Cytometer (Beckton Dickinson, San Jose, CA, USA) and the data analyzed using ModFit LT 3.2 software (Verity Software House; Topsham, ME, USA). Results are shown as representative histograms (from three repetitive experiments) showing percentage DNA distribution in each phase of the cell cycle.

\subsubsection{SDS-PAGE and Western Blot Analysis}

Total cell extracts $(25-50 \mu \mathrm{g})$ from control and LPS and/or AZD-treated Rin-5F cells were separated by $12 \%$ SDS-PAGE [34] and electrophoretically transferred onto nitrocellulose membrane by Western blotting [35]. Transferred proteins were checked by reversible Ponceau $\mathrm{S}$ staining for equal loading and then probed with primary antibodies against cleaved caspase-3, PARP, Hsp-70, HO-1, Atg-5, LC3, p62, Akt, p-Akt, mTOR, p-mTOR, and JNK and p-JNK. Immunoreactive bands were visualized using the appropriate conjugated secondary antibodies. Equal loading of protein was confirmed using beta-actin as loading control. Proteins were visualized by enhanced chemiluminescence using the Sapphire Biomolecular Imager (Azure biosystems, Dublin, CA, USA) or using X-ray films. Relative band intensity was quantified using Image Studio Lite Ver.5.2 (LI-COR Biosciences, Lincoln, NE, USA) and expressed as relative ratios normalized to beta-actin or its respective total proteins as appropriate.

\subsubsection{Statistical Analysis}

Values shown are expressed as mean \pm SD of at least three individual repetitive experiments. Statistical significance of the data was assessed using SPSS software (version 23) by analysis of variance (ANOVA) followed by least significant difference (LSD) posthoc analysis for comparison between the different groups. $p$-value $<0.05$ obtained after post-hoc analysis was considered statistically significant.

\section{Results}

\subsection{Effects of LPS and AZD on Cell Viability, Apoptosis and Cell-Cycle Arrest}

To check the toxicity and effects on cell viability, Rin-5F cells were treated with LPS alone $(1 \mu \mathrm{g} / \mathrm{mL})$ for $24 \mathrm{~h}$ and with different doses of AZD $(10 \mu \mathrm{M}$ to $100 \mu \mathrm{M})$ for different time intervals ( $24 \mathrm{~h}$ and 4 ) and cell viability assessed by MTT assay. Rin-5F cells showed almost $22 \%$ reduction in cell viability (Figure $1 \mathrm{~A})$ after treatment with LPS alone $(1 \mu \mathrm{g} / \mathrm{mL})$ for $24 \mathrm{~h}$. On the other hand, different doses of AZD $(10 \mu \mathrm{M}$ to $100 \mu \mathrm{M})$ caused no significant alterations in cell viability after $24 \mathrm{~h}$ or $48 \mathrm{~h}$ of treatments. These results suggest that AZD is not toxic to the pancreatic $\beta$-cells under the present culture system conditions and hence we used $25 \mu \mathrm{M}$ of AZD for $24 \mathrm{~h}$ in the follow-up experiments.

Next, we investigated the effects of LPS and/or AZD on apoptosis of Rin-5F cells. As shown in Figure 1B, cells treated with $1 \mu \mathrm{g} / \mathrm{mL}$ LPS exhibited around 15\% late apoptotic or necrotic cell death, whereas treatment with $25 \mu \mathrm{M}$ AZD for $24 \mathrm{~h}$ alone or in combination with LPS resulted in less than 10\% late apoptosis. These results suggest some degree of protection by AZD on LPS-induced cell death.

In support, caspase- 3 and caspase- 8 activities were also found to be significantly increased (about 30\%) by LPS alone (Figure 1C), while AZD alone or in combination with LPS caused only a slight increase in the caspase activities. Caspase activation by AZD alone was significantly lower than that with LPS alone, showing the non-toxic effect of AZD at this concentration. AZD also helped in moderately reducing the activation of caspases, again suggesting a protective effect of AZD. 
To further check whether LPS induces cell cycle arrest, we performed cell cycle analysis by staining the cells with propidium iodide and the fluorescence was quantitated using the FACSCanto II Flow Cytometer (Beckton Dickinson, San Jose, CA, USA). As shown in Figure 1D, LPS-treated cells showed an accumulation of cells in the $S$ and G2/M phase (G0/G1-72.8\%, S-13.3\%, and G2/M-12.2\%) compared with the control untreated cells (G0/G1-83.4\%, S-8.8\%, and G2/M-7.2\%). AZD alone showed (G0/G1-83.7\%, S-8.9\%, and G2/M-7.0\%) whereas in combination with LPS, the cell cycle distribution was G0/G1$80.7 \%$, S- $10.5 \%$, and G2/M-8.3\%. This again suggests the apoptotic effect of LPS and confirms the protective effect of AZD.

A

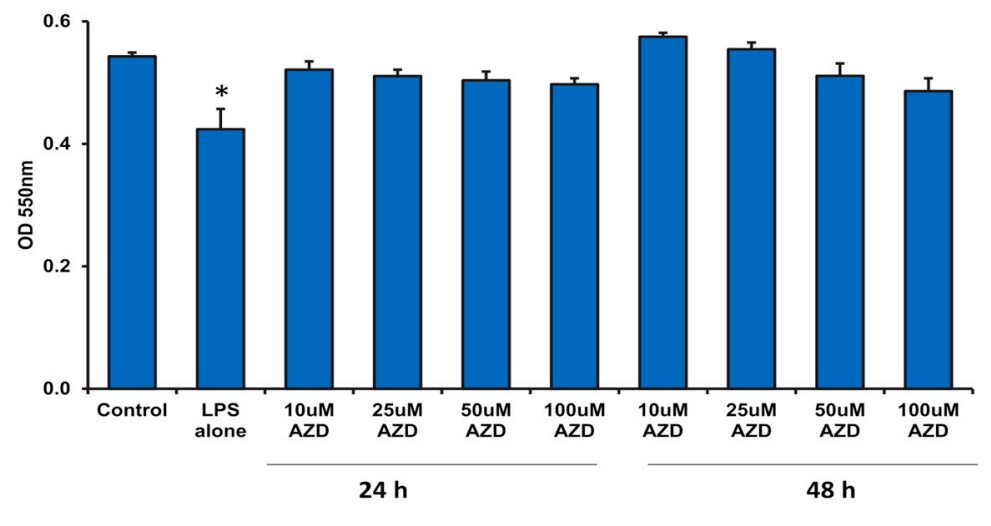

B
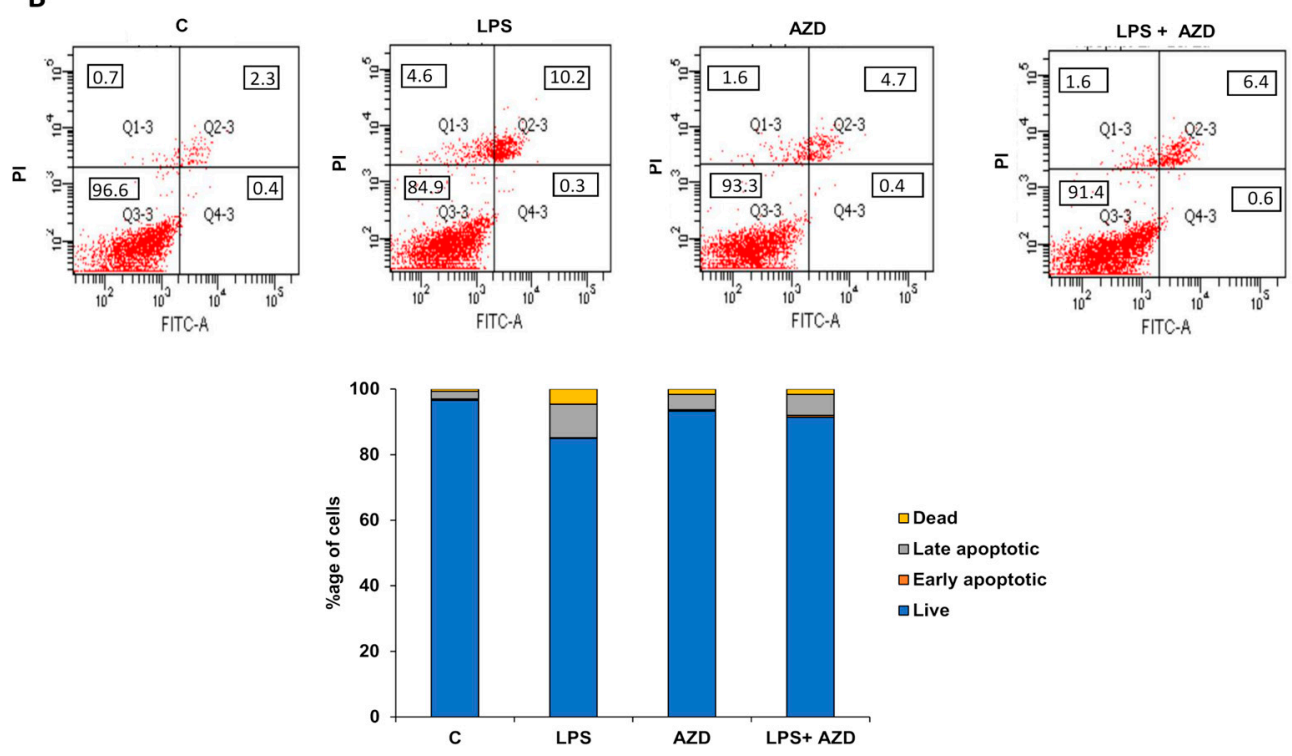

$\square$ Dead

$\square$ Late apoptotic

$\square$ Early apoptotic

a Live

Figure 1. Cont. 


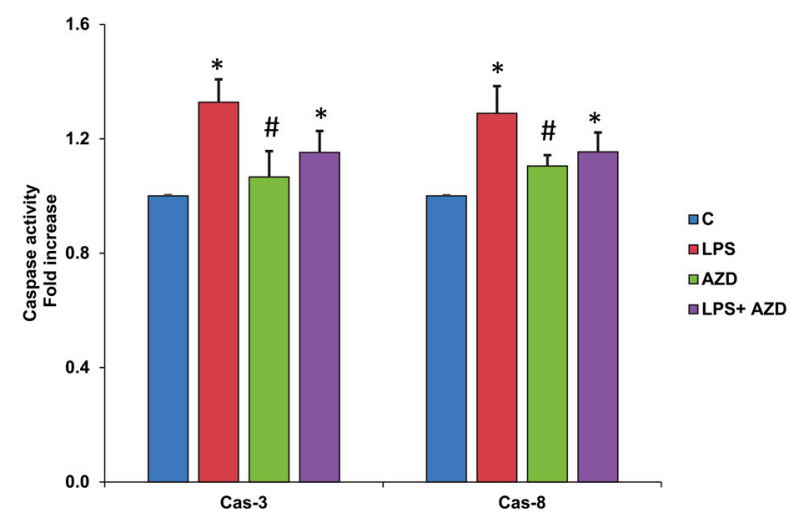

D
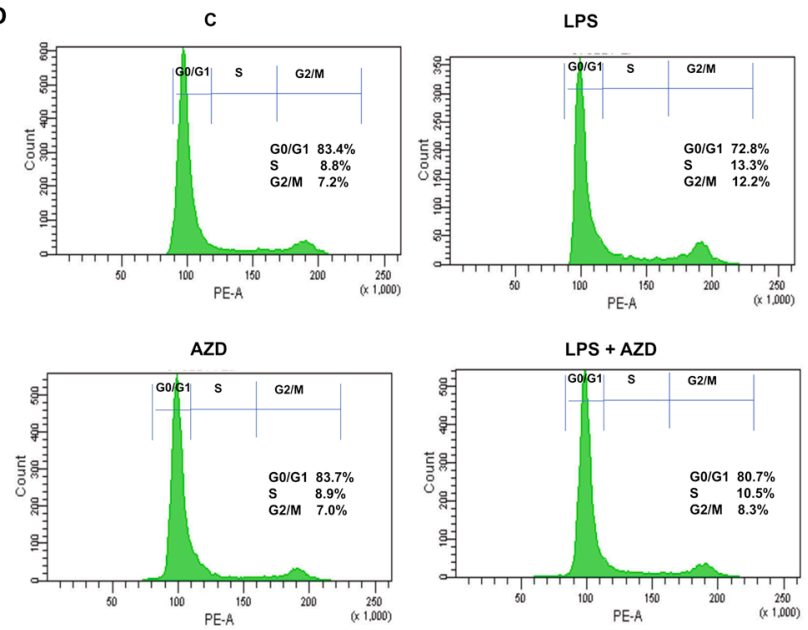

Figure 1. LPS-induced effects on cell viability, apoptosis, and cell-cycle regulation in Rin- $5 \mathrm{~F}$ cells. Rin-5F cells were treated with LPS alone $(1 \mu \mathrm{g} / \mathrm{mL})$ for $24 \mathrm{~h}$ and with different doses of AZD (10 $\mu \mathrm{M}$ to $100 \mu \mathrm{M})$ for different time intervals (24 h and $48 \mathrm{~h}$ ), and MTT assay performed to assess cell viability (A). Apoptosis was measured in the cells treated with LPS $(1 \mu \mathrm{g} / \mathrm{mL})$ with or without AZD $(25 \mu \mathrm{M})$ for $24 \mathrm{~h}$ by flow cytometry (B). A representative dot plot showing percentage of cells in the individual quadrants from three individual repetitive experiments is shown, and the average values are represented as a stacked column chart. Activities of caspases- 3 and -8 were measured in treated and untreated cells colorimetrically using their respective substrates and the chromophore released was measured colorimetrically at a wavelength of $405 \mathrm{~nm}$ (C). Results are expressed as mean \pm SD of three individual repetitive experiments. Asterisks indicate significant differences fixed at $p \leq 0.05$ ( ${ }^{*}$ indicates significant difference relative to control untreated cells, whereas \# indicates significant difference relative to LPS-treated cells). Cell cycle analysis was performed by staining the cells with propidium iodide, and the fluorescence was quantitated using the FACSCanto II Flow Cytometer at an excitation wavelength of $48 \mathrm{~m}$ with detection at $620 \mathrm{~nm}$. Cell cycle data from the resulting histograms were analyzed with ModFit LT 3.2 software (Verity Software House; Topsham, ME) and expressed as percentage DNA distribution in each phase from three individual repetitive experiments. A representative histogram with DNA distribution in each phase is shown in (D).

\subsection{LPS-Induced ROS Generation and Attenuation by AZD}

ROS generation has been known to play a major role in apoptotic cell death. DCFDA staining was performed in cells treated with LPS and/or AZD and analyzed by microscopy, fluorimetry, and flow cytometry. The microscopic analysis in Figure 2A shows increased ROS positive cells after LPS treatment in Rin-5F cells compared with AZD alone or in combination. A marked increase in ROS production after LPS treatment was also confirmed fluorometrically (Figure 2B). When LPS treated cells were incubated with AZD, a significant reduction in the production of DCFDA-sensitive ROS was observed. 
A
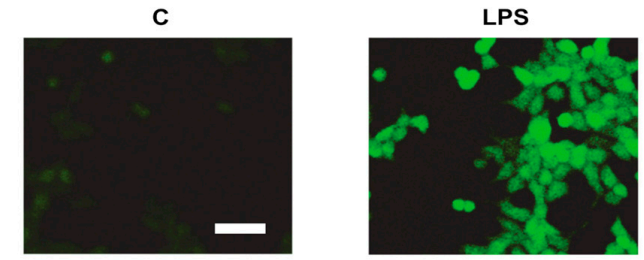

AZD

LPS + AZD

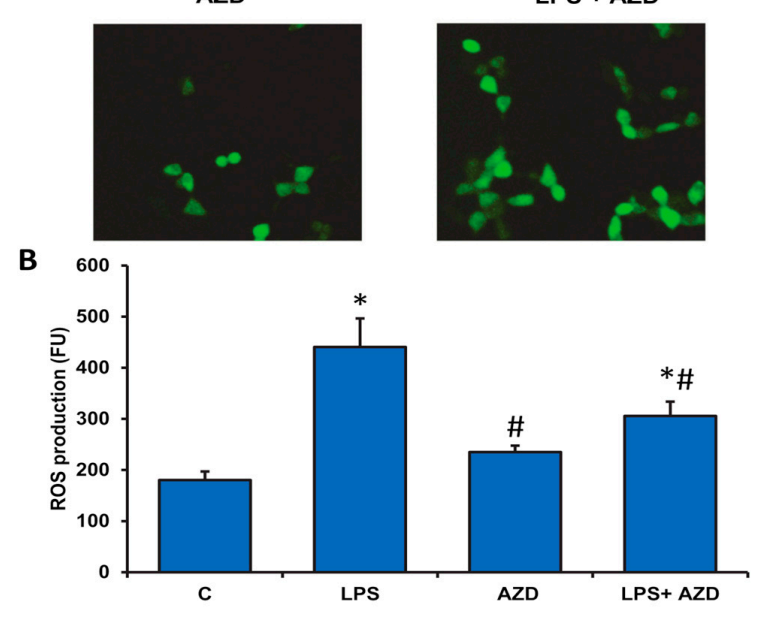

C
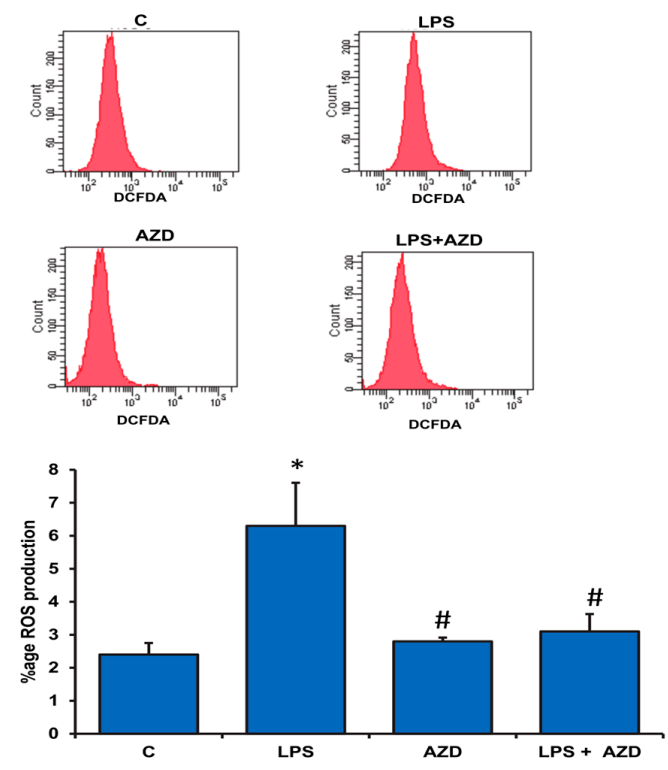

Figure 2. LPS-induced ROS generation in Rin-5F cells. ROS generation in Rin-5F cells treated with LPS alone $(1 \mu \mathrm{g} / \mathrm{mL})$ with or without AZD $(25 \mu \mathrm{M})$ for $24 \mathrm{~h}$ was demonstrated using DCFDA probe microscopically (A) on cells grown on cover slips, fluorimetrically (B) using the ELISA reader, and by flow cytometry (C) using the BD FACSCanto II Flow Cytometer at an excitation wavelength of $488 \mathrm{~nm}$ and an emission wavelength of $525 \mathrm{~nm}$, which showed increased ROS production after LPS treatment. Scale bar in (2A) indicates $50 \mu \mathrm{m}$. Results are expressed as mean \pm SD of three individual repetitive experiments. Asterisks indicate significant differences fixed at $p \leq 0.05$ ( ${ }^{*}$ indicates significant difference relative to control untreated cells, whereas \# indicates significant difference relative to LPS-treated cells).

FACS analysis also demonstrated a marked (three-fold) increase in ROS production after LPS treatment, while AZD treatment alone showed no appreciable production of ROS. LPS-induced ROS was significantly reduced in the presence of AZD (Figure 2C). 


\subsection{LPS-Induced DNA Damage}

DNA fragmentation has been known to be the 'hallmark' for apoptosis. So, to further confirm the apoptotic effect of LPS, we performed DNA fragmentation assay after treatment of Rin-5F cells with LPS and/or AZD. Agarose gel electrophoresis showed DNA breakdown after LPS treatment (Figure 3A). However, a significant reduction was observed when cells were treated with AZD in combination with LPS, suggesting a protection of DNA from LPS-induced cytotoxicity. Cellular DNA damage by ELISA using the cellular DNA fragmentation kit (Sigma, St Louis, MO, USA) also showed increased DNA fragments in the cellular cytoplasm in LPS-treated cells and significant reduction with AZD alone or in combination (Figure 3B). Similarly, Hoechst 33,342 DNA-staining of Rin-5F cells and microscopic visualization exhibited markedly reduced Hoechst-positive cells after LPS treatment in comparison with AZD alone or in combination (Figure 3C).

A
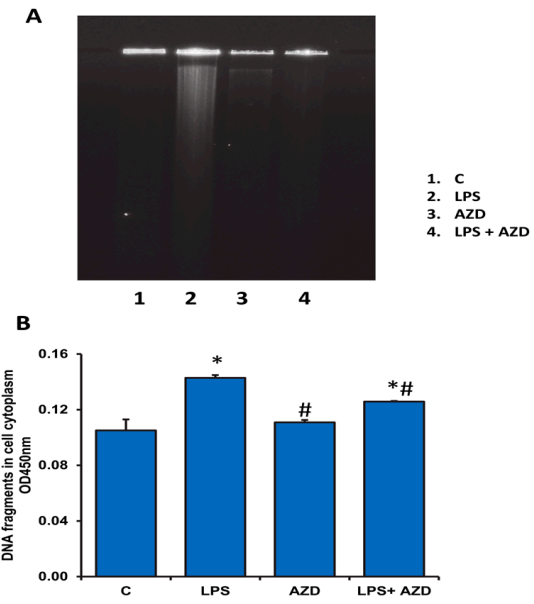

C
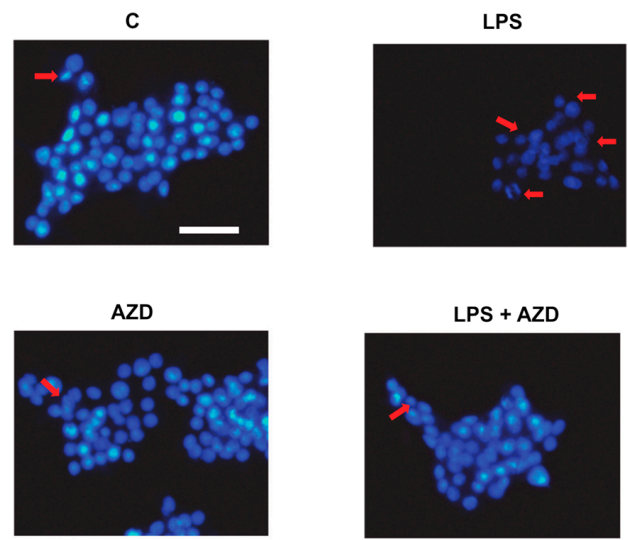

Figure 3. LPS-induced DNA damage in Rin-5F cells. DNA damage was assessed in Rin-5F cells treated with LPS alone $(1 \mu \mathrm{g} / \mathrm{mL})$ with or without AZD $(25 \mu \mathrm{M})$ for $24 \mathrm{~h}$. DNA break-down was confirmed using $2 \%$ agarose gel electrophoresis and staining with ethidium bromide (A). Cellular DNA damage was also assessed by ELISA using the cellular DNA fragmentation kit (B). Results are expressed as mean \pm SD of three individual repetitive experiments. Asterisks indicate significant differences fixed at $p \leq 0.05$ ( ${ }^{*}$ indicates significant difference relative to control untreated cells, whereas \# indicates significant difference relative to LPS-treated cells). Staining of the nuclei was also performed using the Hoechst 33,342 dye and the slides observed under a fluorescence microscope (C). Scale bar indicates $50 \mu \mathrm{m}$. Red arrows indicate apoptotic cells showing damaged nuclei. Representative results from control and LPS alone and AZD with or without LPS from three individual repetitive experiments are shown. 


\subsection{LPS-Induced Expression of Oxidative Stress and Apoptosis Markers}

To further prove the oxidative stress and apoptosis caused by LPS, we checked the expression of oxidative stress, apoptosis, and autophagy markers. As shown in Figure 4A,B, LPS treatment markedly enhanced the expression of cleaved caspase 3 and PARP. AZD treatment in combination with LPS significantly reduced the expression of these apoptotic marker proteins. The expression of Hsp-70, an oxidative stress marker protein, was also increased after LPS treatment, which was normalized after AZD treatment close to control values (Figure 4C). On the other hand, the expression of HO-1, another redox marker protein, was significantly (almost 50\%) reduced after LPS treatment, which came close to control levels after AZD treatment (Figure 4D). AZD treatment alone showed almost no change in the expression of these proteins when compared with control cells.

A

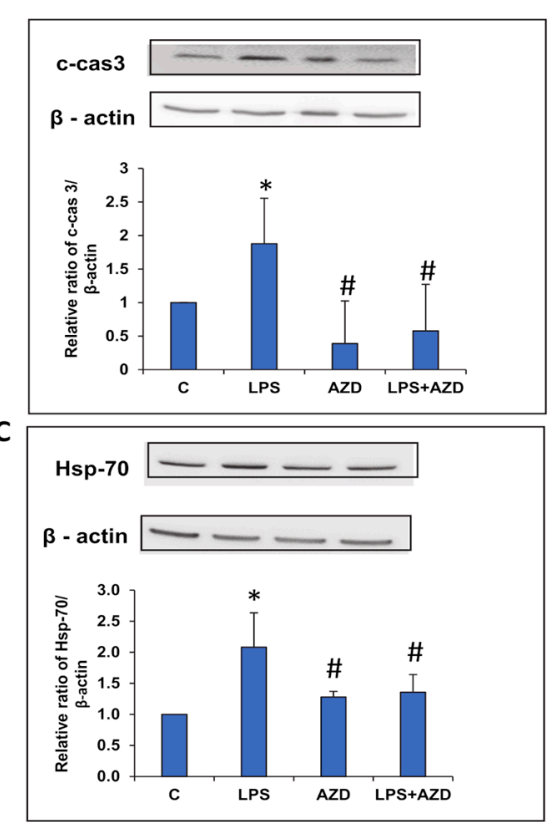

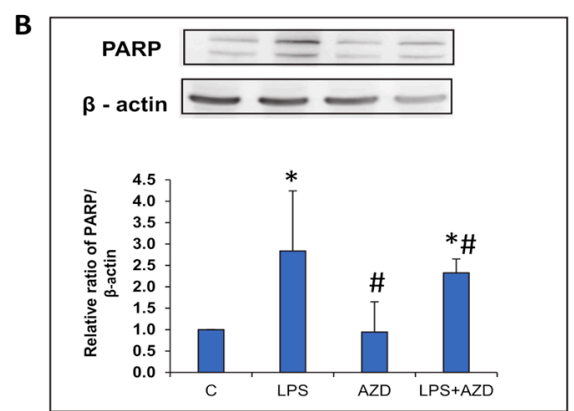

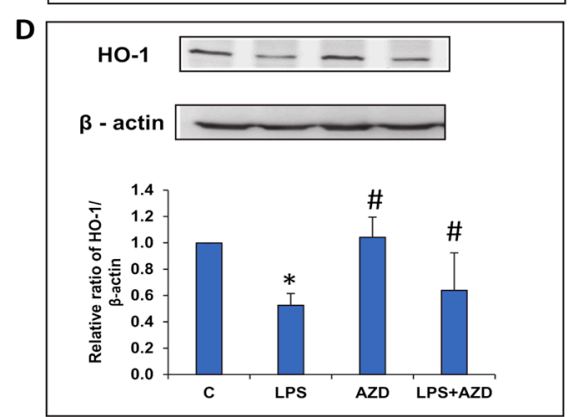

Figure 4. LPS-induced expression of oxidative stress markers. Protein extracts from Rin-5F cells treated with LPS with/without AZD were separated on 12\% SDS-PAGE and transferred on to nitrocellulose paper by Western blotting and protein bands detected using the appropriate primary antibodies. Specific antibodies against cleaved caspase 3 (A), PARP (B), Hsp-70 (C), and HO-1 (D) were used to detect the respective proteins and visualized by enhanced chemiluminescence using the Sapphire Biomolecular Imager (Azure biosystems, Dublin U.S.A) or using X-ray films. Beta actin was used as a loading control. Histograms represent the relative ratios of the quantitated proteins normalized against the loading control. The figures are a representative of at least three individual repetitive experiments. Asterisks indicate significant differences fixed at $p \leq 0.05\left({ }^{*}\right.$ indicates significant difference relative to control untreated cells, whereas \# indicates significant difference relative to LPS-treated cells).

\subsection{LPS-Induced Alterations in the Expression of Autophagy Markers}

We further tried to investigate the regulation of autophagy by LPS. Figure $5 A, B$ shows a four-fold increase in the expression Atg-5 protein and a two-fold increase in the expression of p62 protein respectively, after LPS treatment. AZD, on the other hand, significantly reduced the enhanced expression of these marker proteins. However, the expression of LC3 protein involved in the elongation of autophagosomes was decreased after LPS treatment, while AZD treatment alone enhanced the expression of this protein (Figure 5C). Treatment of cells with AZD in the presence of LPS showed moderate alterations on the expression of the proteins when compared with control cells. These results suggest a restricted autophagic machinery in Rin-5F cells after LPS treatment, perhaps resulting in their increased apoptosis under these conditions. 
A

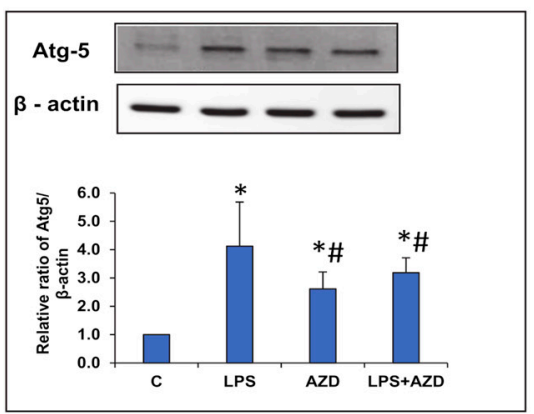

B

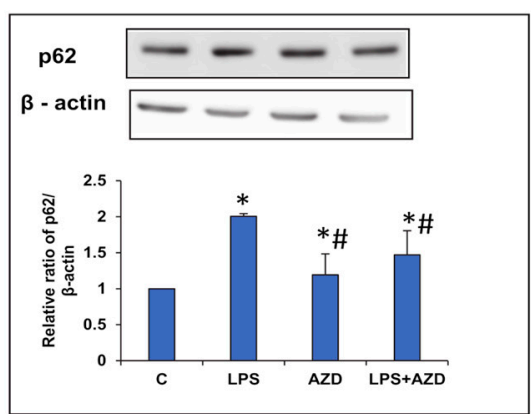

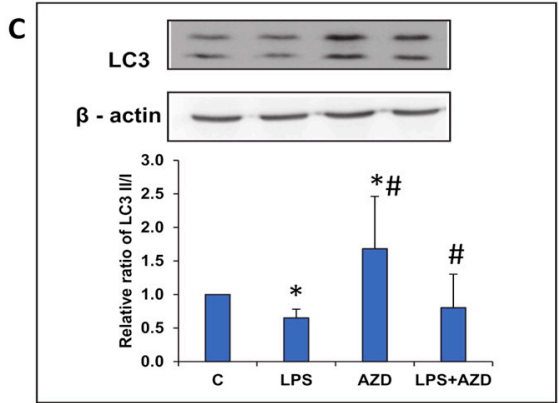

Figure 5. LPS-induced alterations in the expression of autophagy markers. Protein extracts from Rin-5F cells treated with LPS with/without AZD were separated on 12\% SDS-PAGE and transferred on to nitrocellulose paper by Western blotting. Transferred proteins were incubated with primary antibodies against Atg-5 (A), p62 (B), and LC3 (C), and specific proteins visualized by enhanced chemiluminescence using the Sapphire Biomolecular Imager (Azure biosystems, Dublin USA) or using X-ray films. Beta actin was used as a loading control. Histograms represent the relative ratios of the quantitated proteins normalized against the loading control. The figures are representative of at least three individual repetitive experiments. Asterisks indicate significant differences fixed at $p \leq 0.05{ }^{*}$ indicates significant difference relative to control untreated cells, whereas \# indicates significant difference relative to LPS-treated cells).

\subsection{LPS-Induced Alterations of Cell Cycle Progression Markers}

To confirm the cell cycle arrest observed by flow cytometry, we investigated the expression of p53 protein, known to suppress cell cycle progression and cause apoptosis and cell death. Our study demonstrated an increased expression of p53 (Figure 6A) after LPS treatment, which reduced significantly on treatment with AZD. We also observed an increase in the expression of its transcriptional target, p21, which can cause cell cycle arrest at the G1/S phase or G2/M phase (Figure 6B). We further studied the expression of cyclin B1 to confirm cell cycle arrest at the G2/M phase. Consistent with our cell cycle flow cytometry results, we observed an LPS-induced decrease in the expression of cyclin B1 protein, which was increased after AZD treatment, confirming cell cycle arrest at the G2/M phase (Figure 6C). 
A
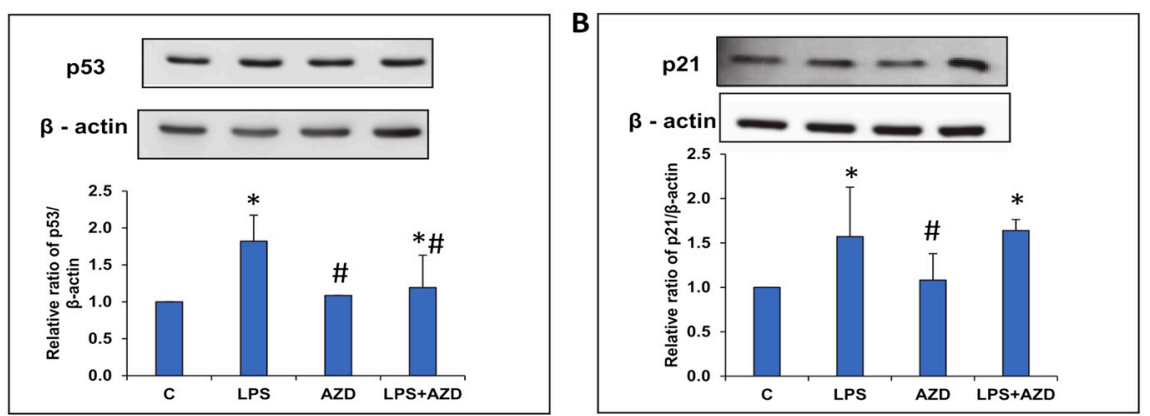

C

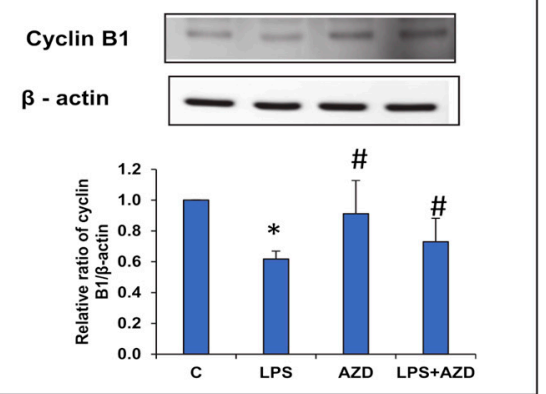

Figure 6. LPS-induced alterations in the expression of cell cycle regulatory markers. Protein extracts from Rin-5F cells treated with LPS with/without AZD were separated on 12\% SDS-PAGE and transferred on to nitrocellulose paper by Western blotting. Transferred proteins were detected using specific antibodies against p53 (A), p21 (B), and cyclin B1 (C), and visualized by enhanced chemiluminescence using the Sapphire Biomolecular Imager (Azure biosystems, Dublin USA) or using X-ray films. Beta actin was used as loading control. Histograms represent the relative ratios of the quantitated proteins normalized against the loading control. The figures are representative of at least three individual repetitive experiments. Asterisks indicate significant differences fixed at $p \leq 0.05$ ( ${ }^{*}$ indicates significant difference relative to control untreated cells, whereas \# indicates significant difference relative to LPS-treated cells).

\subsection{LPS-Induced Alteration of the JNK/Akt and AMPK/mTOR Signaling Pathways}

We further investigated the correlation of apoptosis, ROS production, and autophagy to the expression of cell signaling markers after LPS and AZD treatment alone or in combination. As shown in Figure 7A, phosphorylation of the AMPK protein, a key energy sensor and regulator of autophagy/apoptosis, significantly increased after LPS treatment. This could be due to increased ATP consumption after LPS treatment, which could be the cause for the pathway leading towards apoptosis. Treatment with AZD, alone or in combination, also moderately increased the levels of p-AMPK, compared with the control cells. Concomitant to this, we observed a decrease in the phosphorylation of mammalian target of rapamycin (mTOR), which is also a sensor of metabolic signals (like reactive oxygen species, ATP level) after LPS treatment (Figure 7B). A significant increase in expression was observed after AZD treatment, though it was much lower compared with the control untreated cells. Treatment with AZD alone, however, showed no appreciable change. These results may suggest that cells are facing autophagic regulation and are going into catabolic mode to regulate energy metabolism after LPS treatment. Next, we checked the expression of phosphorylated Akt (p-Akt), which was significantly increased in Rin-5F cells treated with LPS (Figure 7C). No significant change was observed after AZD treatment, though the expression was significantly low in cells treated with AZD alone. A similar increase in the expression of ROS-sensitive JNK signaling protein was observed after LPS treatment, suggesting the activation of downward signaling pathways altering autophagy and apoptosis, which would determine the fate of cells under this type of oxidative/inflammatory stress condition (Figure 7D). Increased phosphorylation of JNK 
protein was also observed after AZD treatment, alone or in combination, though it was significantly lower compared with the LPS-induced cells.

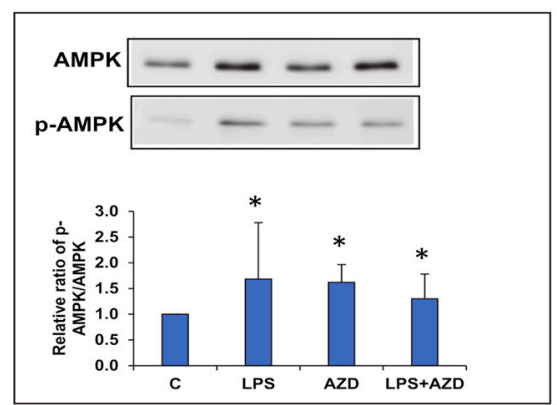

C

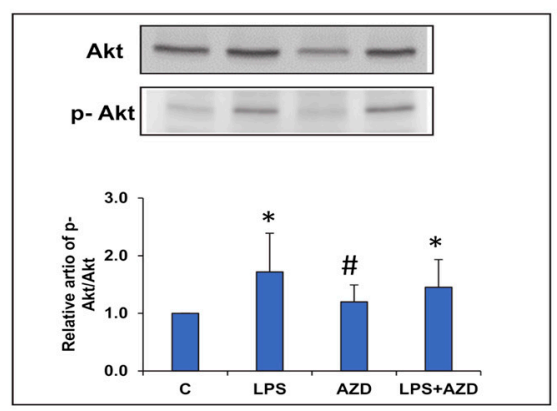

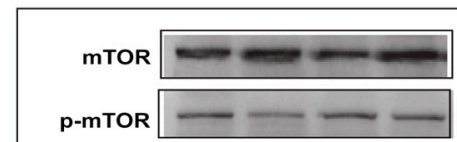

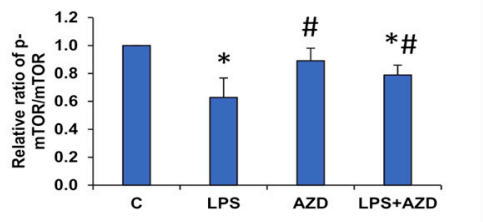

D

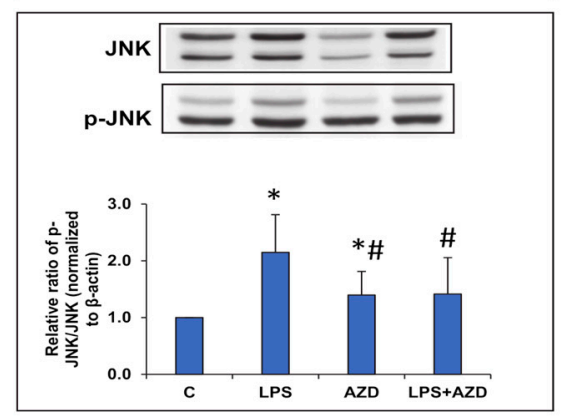

Figure 7. LPS-induced alterations in the expression of cell signaling proteins. Protein extracts from Rin-5F cells treated with LPS with/without AZD were separated on 12\% SDS-PAGE and transferred on to nitrocellulose paper by Western blotting. Specific antibodies against AMPK/pAMPK (A), mTOR/p-MTOR (B), Akt/p-Akt (C), and JNK/p-JNK (D) were used to detect the respective proteins. Beta actin was used as a loading control. Histograms represent the relative ratios of the phosphorylated proteins to total proteins normalized with the loading control. The figures are representative of at least three individual repetitive experiments. Asterisks indicate significant differences fixed at $p \leq 0.05$ ( ${ }^{*}$ indicates significant difference relative to control untreated cells, whereas \# indicates significant difference relative to LPS-treated cells).

\section{Discussion}

$\beta$-cells are metabolically highly active for the generation of ATP and insulin secretion by aerobic energy metabolism and mitochondrial respiratory function, especially in response to elevated blood glucose levels [36,37]. This renders $\beta$-cells susceptible to ROS production and oxidative stress. On the other hand, beta cells are also highly vulnerable towards oxidative stress due to insufficient antioxidant defenses such as lower expression of SOD, GSH-Px, and catalase in comparison with other tissues [38,39]. LPS induces oxidative stress and inflammatory stimuli, which may trigger the induction of autophagy and/or apoptosis. The final outcome of cell death or survival depends on the complex cross-talk between numerous apoptosis-related and autophagy-related proteins and signaling cascades.

Our previous studies, using Rin-5F cells, have shown that these cells exhibit increased inflammatory and oxidative stress responses under glucolipotoxicity conditions, as well as when treated with streptozotocin, a $\beta$-cell damaging diabetogenic agent $[20,23,32]$. In the present study, we further elucidated the molecular mechanism of increased oxidative/inflammatory stress after treating these cells with a bacterial endotoxin, LPS, alone or in combination with a non-toxic concentration of AZD, a known anti-inflammatory phytochemical limonoid extracted from neem. Our results demonstrated increased ROS production, caspase activation, DNA fragmentation, and cell cycle arrest, resulting in increased apoptosis in LPS-treated cells, which was attenuated after AZD treatment.

In order to elucidate the molecular mechanism of LPS-induced cell death and prevention by AZD, we further investigated the expression of proteins involved in oxidative 
stress, autophagy, apoptosis, and cell signaling cascades. These proteins positively or negatively regulate both autophagy and apoptosis. The net effect of whether cells are going to survive by induction of autophagy or go in to autophagy-induced cell death or apoptosis depends on the cell type, stimuli, and escape from cell death due to therapeutic/preventive treatments. Autophagy may play a synergistic role in cell death by providing a membrane-based intracellular platform for caspase processing, by inhibiting the apoptosis by removing apoptotic mitochondria for intrinsic apoptosis, or by degrading the caspases for extrinsic apoptotic pathways. Initially, autophagy functions as an adaptive response to stress, however, in the face of extreme or chronic stress, cells undergo autophagy cell death $[40,41]$. Our results show that LPS-induced cleavage of pro-caspase 3 and PARP to initiate apoptosis was markedly reduced after AZD treatment. This confirmed our observation that Rin-5F cells treated with LPS undergo oxidative stress, as seen by the increased production of ROS followed by DNA fragmentation. This was also supported by the increased expression of oxidative stress marker protein, Hsp-70. On the other hand, HO-1 expression, which is under the regulation of redox-regulating genes, was reduced in LPS-treated cells and enhanced after AZD treatment. HO-1 is a cytoprotective protein known to curtail cytotoxicity caused by oxidative stress and inflammatory reactions and by reducing ROS production [42].

Increased expression of apoptosis-regulating protein p53, was also observed after LPS treatment and AZD caused a reduction of LPS-induced p53. There have been studies suggesting the role of p53 both in extrinsic and intrinsic apoptosis. Increased expression of p53 triggers the expression of apoptotic proteins, resulting in increased apoptosis [43,44]. In the extrinsic pathway, cytoplasmic p53 activates caspase 8 and caspase 3 . Our study also showed increased activities of caspase 8 and caspase 3 proteases after LPS treatment. There are reports showing that p53 activation can promote cell cycle arrest and apoptosis through transcription-independent mechanisms [45,46]. p53 is known to prevent cell cycle progression of cells with damaged DNA. Regarding DNA damage, p53 is activated, which in turn induces the production of p21 protein, which is a cyclin-dependent kinase (Cdk) inhibitor. Cdks are required for cell cycle progression from G1 to $\mathrm{S}$ phase and G2 to M phase. Thus, p53 could induce G1/S phase or G2/M phase cell cycle arrest depending on the cyclin inhibited [47]. This was confirmed in our present study, which revealed a greater proportion of cells in the S and G2/M phase after LPS treatment by flow cytometric analysis compared to the control cells, correlating with the inhibition of cyclin B1. The distribution normalized close to control levels after treatment with AZD. The increased activation of p53 after LPS treatment, accompanied by p21 accumulation and down-regulation of the cell cycle regulatory protein, cyclin B1, resulted in cell cycle arrest at the G2/M phase. Researchers have also shown that p53 represses autophagy through AMPK/mTOR pathways [48]. Our results showed activation in the expression of AMPK associated with a decrease in the expression of mTOR after LPS treatment. However, a decrease in autophagy and increase in apoptosis was observed in these cells. This is in agreement with a study that indicated that inactivation of mTOR can sensitize the proapoptotic response to bacterial infection [49].

We also showed an increased Akt activation/phosphorylation by LPS in Rin-5F cells, however, this was not inhibited after AZD treatment, suggesting the limited role of AZD in Akt-mediated regulation of autophagy/apoptosis/survival in Rin-5F cells under the present experimental conditions. AZD showed no effect on Akt expression in the control untreated cells as well. Also, our study showed an increased expression of AMPK and a decreased activation of mTOR after LPS treatment. There are a number of studies supporting our observation of LPS-induced alterations in AMPK/mTOR signaling various cellular systems [50-53]. We also observed a moderate increase in AMPK activation and a moderate decrease in mTOR phosphorylation after AZD treatment. AZD has also been shown to inhibits pancreatic cancer growth and metastasis through ROS-mediated apoptosis, and also induces autophagy and apoptosis via AKT/mTOR/Atg5 pathways [54,55]. mTOR signaling plays a major role in autophagy as well as in apoptosis, depending on the specific 
cellular conditions and downstream targets such as p53 [44]. These researchers have also shown that alterations in the Akt/mTOR pathways in cancer cells can also induce both autophagy and apoptosis.

Oxidative stress activates JNK1, thus promoting autophagy. However, constitutively active JNK1 prevents the initiation of autophagy. On the contrary, under extreme stress conditions, JNK1 induces apoptosis through caspase 3-dependent pathways. Thus, JNK cell signaling represents an important link between autophagy and apoptosis [56]. Our results showed an increased expression of p-JNK in LPS-treated cells, which was reduced after AZD treatment. AZD treatment alone also increased the expression of $\mathrm{p}-\mathrm{JNK}$, suggesting that AZD itself plays some role in inducing cell death or survival and that it may be related with the type of cell system and activation of other signaling cascades under stress conditions. Our results also demonstrate an altered expression of autophagy-regulating proteins, Atg-5, p62, and LC3. While Atg-5 and p62 expressions were increased after LPS treatment and inhibited after AZD treatment, the LC3 expression was repressed in Rin- $5 \mathrm{~F}$ cells after LPS treatment. AZD treatment alone, on the other hand, increased the expression of LC3 but not when treated along with LPS, suggesting some independent mechanism involved in the regulation of apoptosis or autophagy when treated alone or in combination with LPS. Further studies are needed to elucidate the exact mechanism of action of these proteins involved in the autophagy/apoptosis machinery. LC3 and p62 play important roles as receptors at the phagophore membrane to process protein aggregates and damaged mitochondria for engulfment. Under oxidative stress conditions and with increased ROS, inhibition of autophagy promotes p62, increases the level of caspases, and increases apoptosis [57]. Proteins regulating the elongation process of autophagy have also been shown to participate in the apoptotic pathway. Cleavage of Atg-5 contributes to apoptosis in various cell types. Moreover, $\mathrm{N}$-terminal Atg- 5 cleavage fragments promotes nuclear fragmentation and prevents LC3 accumulation, suggesting the ability of cleaved Atg-5 to induce apoptosis but not autophagy. Similarly, caspase-3-induced cleavage of autophagy-related proteins also induces apoptosis [58]. Autophagy has also been shown to be mutually associated and regulated by the cell cycle $[59,60]$.

\section{Conclusions}

Pancreatic $\beta$-cells have shown high sensitivity towards inflammatory and oxidative stresses. Cells exposed to bacterial endotoxin, LPS, responded by enhanced ROS, DNA degradation, cell cycle dysregulation, and cell death. When treated with an antioxidant phytochemical, AZD, these responses were diverted to repair the damages caused by inducing autophagy-type cellular defense. As shown in the schematic model (Figure 8), autophagy and apoptosis cross-regulate each other through an interconnecting network of cell-signaling proteins and autophagy- and apoptosis-related proteins. Our present study suggests a possible cross-talk between signaling proteins and may have therapeutic implications in better understanding the molecular mechanism of pancreatic $\beta$-cell survival and death under inflammatory and other pathological conditions, including cancer. Further studies on the recognition of the signal cascade and the resulting metabolic consequences will establish precisely the role of the molecular communication in determining the fate of cells. 


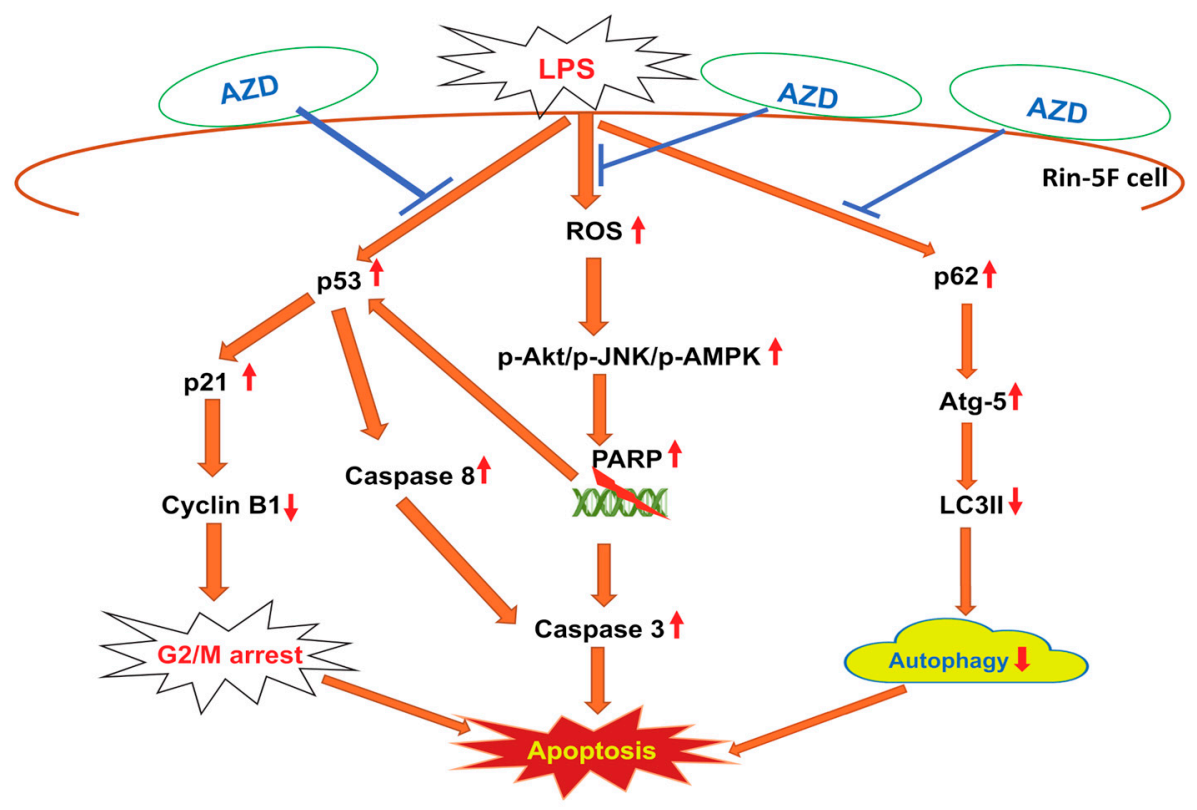

Figure 8. Schematic model representing the cross-talk between signaling proteins involved in the regulation of cell survival and death after LPS-induced oxidative stress and its attenuation by AZD in Rin-5F cells. LPS has been shown to cause increased oxidative stress; activation of the cell signaling kinases; DNA breakdown, causing p53 activation and leading to cell cycle arrest; and apoptosis by activation of caspases. LPS and AZD have also been shown to cause alterations in the expression of autophagy markers. As shown in the model, AZD gives some degree of protection by reducing oxidative stress and enhancing autophagy. ( $\uparrow$ indicates activation whereas, $\downarrow$ indicates a decrease, and $\mathrm{F}$ indicates inhibition).

\section{Limitations}

The main limitation is that this in-vitro study has been done on a single cell line from rats. Further studies on similar cell lines in humans as well as in vivo studies are required to confirm the therapeutic implications of this limonoid. Also, functional analysis needs to be performed to affirm the cross-talk between cell signaling proteins to understand better the molecular mechanism/pathway of pancreatic cell death and survival under pathological conditions.

Author Contributions: Conceptualization, H.R.; Data curation, A.J. and H.R.; Formal analysis, A.J. and H.R.; Funding acquisition, H.R.; Supervision, H.R.; Writing-first draft, H.R.; Writing-review \& editing, H.R. and A.J. All authors have read and agreed to the published version of the manuscript.

Funding: This research was funded by the Research Committee, College of Medicine and Health Sciences, UAE University, Al Ain, UAE (HR-31M464).

Institutional Review Board Statement: Not applicable.

Informed Consent Statement: Not applicable.

Data Availability Statement: All data provided in the manuscript.

Conflicts of Interest: The authors declare no conflict of interest.

\section{References}

1. Matsuda, N.; Hattori, Y. Systemic Inflammatory Response Syndrome (SIRS): Molecular Pathophysiology and Gene Therapy. J. Pharmacol. Sci. 2006, 101, 189-198. [CrossRef]

2. Li, S.; Dai, Q.; Zhang, S.; Liu, Y.; Yu, Q.; Tan, F.; Lu, S.; Wang, Q.; Chen, J.; Huang, H.; et al. Ulinastatin Attenuates LPS-Induced Inflammation in Mouse Macrophage RAW264.7 Cells by Inhibiting the JNK/NF-KB Signaling Pathway and Activating the PI3K/Akt/Nrf2 Pathway. Acta Pharmacol. Sin. 2018, 39, 1294-1304. [CrossRef] [PubMed] 
3. Ghonime, M.G.; Shamaa, O.R.; Das, S.; Eldomany, R.A.; Fernandes-Alnemri, T.; Alnemri, E.S.; Gavrilin, M.A.; Wewers, M.D. Inflammasome Priming by Lipopolysaccharide Is Dependent upon ERK Signaling and Proteasome Function. J.Immunol. 2014, 192, 3881-3888. [CrossRef] [PubMed]

4. $\quad$ Chen, C.-C.; Lin, J.-T.; Cheng, Y.-F.; Kuo, C.-Y.; Huang, C.-F.; Kao, S.-H.; Liang, Y.-J.; Cheng, C.-Y.; Chen, H.-M. Amelioration of LPS-Induced Inflammation Response in Microglia by AMPK Activation. Biomed Res. Int. 2014, 2014, 692061. [CrossRef] [PubMed]

5. Fan, K.; Lin, L.; Ai, Q.; Wan, J.; Dai, J.; Liu, G.; Tang, L.; Yang, Y.; Ge, P.; Jiang, R.; et al. Lipopolysaccharide-Induced Dephosphorylation of AMPK-Activated Protein Kinase Potentiates Inflammatory Injury via Repression of ULK1-Dependent Autophagy. Front. Immunol. 2018, 9, 1464. [CrossRef]

6. Zhang, X.; Liang, T.; Yang, W.; Zhang, L.; Wu, S.; Yan, C.; Li, Q. Astragalus Membranaceus Injection Suppresses Production of Interleukin-6 by Activating Autophagy through the AMPK-MTOR Pathway in Lipopolysaccharide-Stimulated Macrophages. Oxid. Med. Cell. Longev. 2020, 2020, 1-19. [CrossRef]

7. Fest, J.; Ruiter, R.; Mulder, M.; Groot Koerkamp, B.; Ikram, M.A.; Stricker, B.H.; van Eijck, C.H.J. The Systemic ImmuneInflammation Index Is Associated with an Increased Risk of Incident Cancer-A Population-Based Cohort Study. Int. J. Cancer 2020, 146, 692-698. [CrossRef] [PubMed]

8. Martín-Núñez, E.; Donate-Correa, J.; Ferri, C.; López-Castillo, Á.; Delgado-Molinos, A.; Hernández-Carballo, C.; Pérez-Delgado, N.; Rodríguez-Ramos, S.; Cerro-López, P.; Tagua, V.G.; et al. Association between Serum Levels of Klotho and Inflammatory Cytokines in Cardiovascular Disease: A Case-Control Study. Aging 2020, 12, 1952-1964. [CrossRef]

9. Montane, J.; Cadavez, L.; Novials, A. Stress and the Inflammatory Process: A Major Cause of Pancreatic Cell Death in Type 2 Diabetes. Diab. Metab. Syndr. Obes. 2014, 7, 25-34. [CrossRef]

10. Turner, M.D.; Nedjai, B.; Hurst, T.; Pennington, D.J. Cytokines and Chemokines: At the Crossroads of Cell Signalling and Inflammatory Disease. Biochim. Biophys. Acta 2014, 1843, 2563-2582. [CrossRef]

11. Lima-Cabello, E.; Alché, J.D.; Morales-Santana, S.; Clemente, A.; Jimenez-Lopez, J.C. Narrow-Leafed Lupin (Lupinus Angustifolius L.) Seeds Gamma-Conglutin Is an Anti-Inflammatory Protein Promoting Insulin Resistance Improvement and Oxidative Stress Amelioration in PANC-1 Pancreatic Cell-Line. Antioxidants 2020, 9, 12. [CrossRef] [PubMed]

12. Pan, L.; Yu, L.; Wang, L.; He, J.; Sun, J.; Wang, X.; Wang, H.; Bai, Z.; Feng, H.; Pei, H. Inflammatory Stimuli Promote Oxidative Stress in Pancreatic Acinar Cells via Toll-like Receptor 4/Nuclear Factor-KB Pathway. Int. J. Mol. Med. 2018, 42, 3582-3590. [CrossRef]

13. Acosta-Montaño, P.; Rodríguez-Velázquez, E.; Ibarra-López, E.; Frayde-Gómez, H.; Mas-Oliva, J.; Delgado-Coello, B.; Rivero, I.A.; Alatorre-Meda, M.; Aguilera, J.; Guevara-Olaya, L.; et al. Fatty Acid and Lipopolysaccharide Effect on Beta Cells Proteostasis and Its Impact on Insulin Secretion. Cells 2019, 8, 884. [CrossRef] [PubMed]

14. Jiang, H.; Ma, Y.; Fu, L.; Wang, J.; Wang, L.; Fan, M.; Huang, K.; Zhang, Y.; Peng, H. Influence of Lipopolysaccharides on Autophagy and Inflammation in Pancreatic Islet Cells of Mice Fed by High-Fat Diet. Eur. J. Inflamm. 2018, 16, 1721727X17754180. [CrossRef]

15. Raza, H.; Prabu, S.K.; Robin, M.-A.; Avadhani, N.G. Elevated Mitochondrial Cytochrome P450 2E1 and Glutathione S-Transferase A4-4 in Streptozotocin-Induced Diabetic Rats: Tissue-Specific Variations and Roles in Oxidative Stress. Diabetes 2004, 53, 185-194. [CrossRef] [PubMed]

16. Raza, H.; Prabu, S.K.; John, A.; Avadhani, N.G. Impaired Mitochondrial Respiratory Functions and Oxidative Stress in Streptozotocin-Induced Diabetic Rats. Int. J. Mol. Sci. 2011, 12, 3133-3147. [CrossRef] [PubMed]

17. Raza, H.; John, A.; Howarth, F.C. Increased Metabolic Stress in Zucker Diabetic Fatty Rat Kidney and Pancreas. Cell. Physiol. Biochem. 2013, 32, 1610-1620. [CrossRef]

18. Raza, H.; John, A.; Howarth, F.C. Alterations in Glutathione Redox Metabolism, Oxidative Stress, and Mitochondrial Function in the Left Ventricle of Elderly Zucker Diabetic Fatty Rat Heart. Int. J. Mol. Sci. 2012, 13, 16241-16254. [CrossRef] [PubMed]

19. Raza, H.; John, A.; Shafarin, J.; Howarth, F.C. Exercise-Induced Alterations in Pancreatic Oxidative Stress and Mitochondrial Function in Type 2 Diabetic Goto-Kakizaki Rats. Physiol. Rep. 2016, 4, e12751. [CrossRef]

20. Nahdi, A.M.T.A.; John, A.; Raza, H. Elucidation of Molecular Mechanisms of Streptozotocin-Induced Oxidative Stress, Apoptosis, and Mitochondrial Dysfunction in Rin-5F Pancreatic $\beta$-Cells. Oxid. Med. Cell. Longev. 2017, 2017, 7054272. [CrossRef]

21. Al-Nahdi, A.M.T.; John, A.; Raza, H. Cytoprotective Effects of N-Acetylcysteine on Streptozotocin-Induced Oxidative Stress and Apoptosis in RIN-5F Pancreatic $\beta$-Cells. Cell. Physiol. Biochem. 2018, 51, 201-216. [CrossRef] [PubMed]

22. Raza, H.; John, A.; Shafarin, J. NAC Attenuates LPS-Induced Toxicity in Aspirin-Sensitized Mouse Macrophages via Suppression of Oxidative Stress and Mitochondrial Dysfunction. PLoS ONE 2014, 9, e103379. [CrossRef]

23. Al-Nahdi, A.M.T.; John, A.; Raza, H. Streptozotocin-Induced Molecular and Metabolic Targets in Pancreatic Beta-Cell Toxicity. Hamdan Med J. 2019, 12, 65. [CrossRef]

24. Ponnusamy, S.; Haldar, S.; Mulani, F.; Zinjarde, S.; Thulasiram, H.; RaviKumar, A. Gedunin and Azadiradione: Human Pancreatic Alpha-Amylase Inhibiting Limonoids from Neem (Azadirachta Indica) as Anti-Diabetic Agents. PLoS ONE 2015, 10, e0140113. [CrossRef] [PubMed]

25. Dubey, R.; Patil, K.; Dantu, S.C.; Sardesai, D.M.; Bhatia, P.; Malik, N.; Acharya, J.D.; Sarkar, S.; Ghosh, S.; Chakrabarti, R.; et al. Azadirachtin Inhibits Amyloid Formation, Disaggregates Pre-Formed Fibrils and Protects Pancreatic $\beta$-Cells from Human Islet Amyloid Polypeptide/Amylin-Induced Cytotoxicity. Biochem. J. 2019, 476, 889-907. [CrossRef] [PubMed] 
26. Sophia, J.; Kowshik, J.; Dwivedi, A.; Bhutia, S.K.; Manavathi, B.; Mishra, R.; Nagini, S. Nimbolide, a Neem Limonoid Inhibits Cytoprotective Autophagy to Activate Apoptosis via Modulation of the PI3K/Akt/GSK-3 $\beta$ Signalling Pathway in Oral Cancer. Cell Death Dis. 2018, 9, 1087. [CrossRef] [PubMed]

27. Schumacher, M.; Cerella, C.; Reuter, S.; Dicato, M.; Diederich, M. Anti-Inflammatory, pro-Apoptotic, and Anti-Proliferative Effects of a Methanolic Neem (Azadirachta Indica) Leaf Extract Are Mediated via Modulation of the Nuclear Factor-KB Pathway. Genes Nutr. 2011, 6, 149-160. [CrossRef]

28. Patra, A.; Satpathy, S.; Hussain, M.D. Nanodelivery and Anticancer Effect of a Limonoid, Nimbolide, in Breast and Pancreatic Cancer Cells. Int. J. Nanomed. 2019, 14, 8095-8104. [CrossRef] [PubMed]

29. Alnahdi, A.; John, A.; Raza, H. Mitigation of Glucolipotoxicity-Induced Apoptosis, Mitochondrial Dysfunction, and Metabolic Stress by N-Acetyl Cysteine in Pancreatic $\beta$-Cells. Biomolecules 2020, 10, 239. [CrossRef]

30. He, W.; Rebello, O.; Savino, R.; Terracciano, R.; Schuster-Klein, C.; Guardiola, B.; Maedler, K. TLR4 triggered complex inflammation in human pancreatic islets. BBA-Mol. Basis Dis. 2019, 1865, 86-97. [CrossRef]

31. Raza, H.; John, A.; Shafarin, J. Potentiation of LPS-Induced Apoptotic Cell Death in Human Hepatoma HepG2 Cells by Aspirin via ROS and Mitochondrial Dysfunction: Protection by N-Acetyl Cysteine. PLoS ONE 2016, 11, e0159750. [CrossRef]

32. Alnahdi, A.; John, A.; Raza, H. N-Acetyl Cysteine Attenuates Oxidative Stress and Glutathione-Dependent Redox Imbalance Caused by High Glucose/High Palmitic Acid Treatment in Pancreatic Rin-5F Cells. PLoS ONE 2019, 14, e0226696. [CrossRef] [PubMed]

33. Piazza, G.A.; Rahm, A.K.; Finn, T.S.; Fryer, B.H.; Li, H.; Stoumen, A.L.; Pamukcu, R.; Ahnen, D.J. Apoptosis Primarily Accounts for the Growth-Inhibitory Properties of Sulindac Metabolites and Involves a Mechanism That Is Independent of Cyclooxygenase Inhibition, Cell Cycle Arrest, and P53 Induction. Cancer Res. 1997, 57, 2452-2459.

34. Laemmli, U.K. Cleavage of Structural Proteins during the Assembly of the Head of Bacteriophage T4. Nature 1970, 227, 680-685. [CrossRef] [PubMed]

35. Towbin, H.; Staehelin, T.; Gordon, J. Electrophoretic Transfer of Proteins from Polyacrylamide Gels to Nitrocellulose Sheets: Procedure and Some Applications. Proc. Natl. Acad. Sci. USA 1979, 76, 4350-4354. [CrossRef] [PubMed]

36. American Diabetic Association. Diagnosis and Classification of Diabetes Mellitus. Diab. Care 2011, 34, S62-S69. [CrossRef] [PubMed]

37. Tiedge, M.; Lortz, S.; Drinkgern, J.; Lenzen, S. Relation between Antioxidant Enzyme Gene Expression and Antioxidative Defense Status of Insulin-Producing Cells. Diabetes 1997, 46, 1733-1742. [CrossRef]

38. Tiedge, M.; Lortz, S.; Munday, R.; Lenzen, S. Complementary Action of Antioxidant Enzymes in the Protection of Bioengineered Insulin-Producing RINm5F Cells against the Toxicity of Reactive Oxygen Species. Diabetes 1998, 47, 1578-1585. [CrossRef]

39. Lenzen, S.; Drinkgern, J.; Tiedge, M. Low Antioxidant Enzyme Gene Expression in Pancreatic Islets Compared with Various Other Mouse Tissues. Free Radic. Biol. Med. 1996, 20, 463-466. [CrossRef]

40. Mukhopadhyay, S.; Panda, P.K.; Sinha, N.; Das, D.N.; Bhutia, S.K. Autophagy and Apoptosis: Where Do They Meet? Apoptosis 2014, 19, 555-566. [CrossRef] [PubMed]

41. Tsapras, P.; Nezis, I.P. Caspase Involvement in Autophagy. Cell Death Differ. 2017, 24, 1369-1379. [CrossRef] [PubMed]

42. Huang, C.-Y.; Deng, J.-S.; Huang, W.-C.; Jiang, W.-P.; Huang, G.-J. Attenuation of Lipopolysaccharide-induced Acute Lung Injury by Hispolon in Mice, through Regulating the TLR4/P13K/Akt/mTOR and Keap/Nrf2/HO-1 Pathways, and Suppressing Oxidative Stress-Mediated ER Stress-Induced Apoptosis and Autophagy. Nutrients 2020, 12, 1742. [CrossRef] [PubMed]

43. Maiuri, M.C.; Zalckvar, E.; Kimchi, A.; Kroemer, G. Self-Eating and Self-Killing: Crosstalk between Autophagy and Apoptosis. Nat. Rev. Mol. Cell Biol. 2007, 8, 741-752. [CrossRef]

44. Eisenberg-Lerner, A.; Bialik, S.; Simon, H.-U.; Kimchi, A. Life and Death Partners: Apoptosis, Autophagy and the Cross-Talk between Them. Cell. Death Differ. 2009, 16, 966-975. [CrossRef]

45. Speidel, D. Transcription-Independent P53 Apoptosis: An Alternative Route to Death. Trends Cell Biol. 2010, 20, 14-24. [CrossRef] [PubMed]

46. D'Angelo, B.; Astarita, C.; Boffo, S.; Massaro-Giordano, M.; Antonella Ianuzzi, C.; Caporaso, A.; Macaluso, M.; Giordano, A. LPS-Induced Inflammatory Response Triggers Cell Cycle Reactivation in Murine Neuronal Cells through Retinoblastoma Proteins Induction. Cell Cycle 2017, 16, 2330-2336. [CrossRef] [PubMed]

47. JingFei, H.; KeJuan, S.; HaiYi, L.; MeiYing, H.; GuoHua, Z. Antiproliferative Effect of Azadirachtin A on Spodoptera Litura Sl-1 Cell Line through Cell Cycle Arrest and Apoptosis Induced by up-Regulation of P53. Pestic. Biochem. Phys. 2011, 99, 16-24.

48. Tasdemir, E.; Maiuri, M.C.; Galluzzi, L.; Vitale, I.; Djavaheri-Mergny, M.; D’Amelio, M.; Criollo, A.; Morselli, E.; Zhu, C.; Harper, F.; et al. Regulation of Autophagy by Cytoplasmic P53. Nat. Cell Biol. 2008, 10, 676-687. [CrossRef]

49. Fielhaber, J.A.; Carroll, S.F.; Dydensborg, A.B.; Shourian, M.; Triantafillopoulos, A.; Harel, S.; Hussain, S.N.; Bouchard, M.; Qureshi, S.T.; Kristof, A.S. Inhibition of Mammalian Target of Rapamycin Augments Lipopolysaccharide-Induced Lung Injury and Apoptosis. J.Immunol. 2012, 188, 4535-4542. [CrossRef]

50. Li, Y.; Wang, S.; Gao, X.; Zhao, Y.; Li, Y.; Yang, B.; Zhang, N.; Ma, L. Octreotide Alleviates Autophagy by Up-Regulation of MicroRNA-101 in Intestinal Epithelial Cell Line Caco-2. Cell. Physiol. Biochem. 2018, 49, 1352-1363. [CrossRef] [PubMed]

51. Cao, J.; Xue, R.; He, B. Quercetin Protects Oral Mucosal Keratinocytes against Lipopolysaccharide-Induced Inflammatory Toxicity by Suppressing the AKT/AMPK/MTOR Pathway. Immunopharmacol. Immunotoxicol. 2021, 43, 519-526. [CrossRef] 
52. Lv, H.; Liu, Q.; Wen, Z.; Feng, H.; Deng, X.; Ci, X. Xanthohumol Ameliorates Lipopolysaccharide (LPS)-Induced Acute Lung Injury via Induction of AMPK/GSK3 $3-N r f 2$ Signal Axis. Redox Biol. 2017, 12, 311-324. [CrossRef] [PubMed]

53. Wang, X.-H.; Zhang, Z.-H.; Cai, X.-L.; Ye, P.; Feng, X.; Liu, T.-T.; Li, X.-Z. Lipopolysaccharide Induces Autophagy by Targeting the AMPK-MTOR Pathway in Human Nasal Epithelial Cells. Biomed. Pharmacother. 2017, 96, 899-904. [CrossRef] [PubMed]

54. Shao, X.; Lai, D.; Zhang, L.; Xu, H. Induction of Autophagy and Apoptosis via PI3K/AKT/TOR Pathways by Azadirachtin A in Spodoptera Litura Cells. Sci. Rep. 2016, 6, 35482. [CrossRef] [PubMed]

55. Subramani, R.; Gonzalez, E.; Arumugam, A.; Nandy, S.; Gonzalez, V.; Medel, J.; Camacho, F.; Ortega, A.; Bonkoungou, S.; Narayan, M.; et al. Nimbolide Inhibits Pancreatic Cancer Growth and Metastasis through ROS-Mediated Apoptosis and Inhibition of Epithelial-to-Mesenchymal Transition. Sci. Rep. 2016, 6, 19819. [CrossRef] [PubMed]

56. Wei, Y.; Sinha, S.; Levine, B. Dual Role of JNK1-Mediated Phosphorylation of Bcl-2 in Autophagy and Apoptosis Regulation. Autophagy 2008, 4, 949-951. [CrossRef]

57. Zhang, Y.-B.; Zhao, W.; Zeng, R.-X. Autophagic Degradation of Caspase-8 Protects U87MG Cells against H2O2-Induced Oxidative Stress. Asian Pac. J. Cancer Prev. 2013, 14, 4095-4099. [CrossRef] [PubMed]

58. Bhutia, S.K.; Dash, R.; Das, S.K.; Azab, B.; Su, Z.; Lee, S.-G.; Grant, S.; Yacoub, A.; Dent, P.; Curiel, D.T.; et al. Mechanism of Autophagy to Apoptosis Switch Triggered in Prostate Cancer Cells by Antitumor Cytokine Melanoma Differentiation-Associated Gene $7 /$ Interleukin-24. Cancer Res. 2010, 70, 3667-3676. [CrossRef] [PubMed]

59. Zheng, X.; Li, W.; Xu, H.; Liu, J.; Ren, L.; Yang, Y.; Li, S.; Wang, J.; Ji, T.; Du, G. Sinomenine Ester Derivative Inhibits Glioblastoma by Inducing Mitochondria-dependent Apoptosis and Autophagy by P13K/AKT/mTOR and AMPK/mTOR pathway. Acta Pharm. Sin. B 2021, 11, 3465-3480. [CrossRef]

60. Azzopardi, M.; Farrugia, G.; Balzan, R. Cell-cycle involvement in autophagy and apoptosis in yeast. Mech. Ageing Dev. 2017, 161, 211-224. [CrossRef] [PubMed] 